\title{
Article
}

\section{Tensile Creep of Cement and Concrete Composites: Monitoring by Means of 2D-Digital Image Correlation}

\author{
Andina Sprince ${ }^{1, *(\mathbb{C}}$, Tomass Kozlovskis ${ }^{1}$, Rihards Gailitis ${ }^{1}\left(\mathbb{D}\right.$, Juozas Valivonis ${ }^{2}$, Kinga Korniejenko ${ }^{3}(\mathbb{D}$ \\ and Arnaud Castel ${ }^{4}$ \\ 1 Department of Civil Engineering, Riga Technical University, LV-1658 Riga, Latvia; \\ tomass.kozlovskis@rtu.lv (T.K.); rihards.gailitis@edu.rtu.lv (R.G.) \\ 2 Department of Reinforced Concrete Construction structures and Geotechnics, \\ Vilnius Gediminas Technical University, LT-10223 Vilnius, Lithuania; juozas.valivonis@vilniustech.lt \\ 3 Faculty of Material Engineering and Physics, Cracow University of Technology, 31-864 Cracow, Poland; \\ kinga.korniejenko@pk.edu.pl \\ 4 School of Civil and Environmental Engineering, University of Technology Sydney (UTS), \\ Sydney, NSW 2007, Australia; arnaud.castel@uts.edu.au \\ * Correspondence: andina.sprince@rtu.lv
}

check for

updates

Citation: Sprince, A.; Kozlovskis, T.; Gailitis, R.; Valivonis, J.;

Korniejenko, K.; Castel, A. Tensile

Creep of Cement and Concrete

Composites: Monitoring by Means of

2D-Digital Image Correlation. Appl.

Sci. 2021, 11, 8334. https://doi.org/

10.3390/app11188334

Academic Editor: Kang Su Kim

Received: 4 August 2021

Accepted: 28 August 2021

Published: 8 September 2021

Publisher's Note: MDPI stays neutral with regard to jurisdictional claims in published maps and institutional affiliations.

Copyright: (c) 2021 by the authors. Licensee MDPI, Basel, Switzerland. This article is an open access article distributed under the terms and conditions of the Creative Commons Attribution (CC BY) license (https:/ / creativecommons.org/licenses/by/ $4.0 /)$.

\begin{abstract}
Creep and shrinkage of Cement and Concrete Composites (CCC) are significant properties that need to be considered to use these materials in practice. Many previous scientific studies revealed CCC creep characteristics under sustained compression and shrinkage, using traditional test methods from design standards. Because of the complexity of experimental procedures, CCC creep in tension has not been studied as close. Furthermore, there is no unified standard that proposes applicable testing methods or specific testing apparatus. This study examines the suitability of 2D—Digital Image Correlation (DIC) to observe the creep deformations of specimens under tension. Ordinary Portland cement (OPC) mortar with $1 \%$ polyvinyl alcohol (PVA) fibres has been investigated in the research. Compact tension (CT) specimens $150 \times 150 \times 12 \mathrm{~mm}$ (with a notch) were used. Creep deformations under sustained uniaxial tension (applied loading corresponding to $60 \%$ of the ultimate strength) were measured. DIC images were captured using an entry/mid-level DSLR camera. Results show that DIC is suitable for studying uniaxial tensile creep of cement and concrete composites. Deformation of specimens in tension was similar to that measured using the conventional method (using surface-attached gauges).
\end{abstract}

Keywords: cement and concrete composites; creep; direct tensile test; digital image correlation; 2D-DIC

\section{Introduction}

The signification of Cement and Concrete Composites (CCC) can vary and often have a broad meaning in the scientific field. European standard EN 197-1 [1] lists 27 common types of cement, divided into five groups (ordinary Portland cement and cement mixes) with a notation that those are hydraulic binders [2]. Furthermore, the ASTM C 125 [3] standard acknowledges concrete that primarily employs hydraulic cement as a binding medium but does not entirely exclude the existence of non-hydraulic binders [4]. From a scientific point of view, materials such as aluminosilicates and calcium silicates are also recognised as cementitious materials, even though they do not imply hydration as the main hardening process. The former is a powdered substance, also called alkali-activated cement or geopolymer [5,6], whereas the latter hardens through a carbonation process [7]. Because of the above, concrete, mortar and grout are composite materials that can contain either hydraulic or non-hydraulic binder. In this research paper, the term concrete composite is associated with any concrete mix (containing fibres or other types of reinforcement, special aggregates and polymers) that can be viewed as ageing viscoelastic materials [8-10]. 
Viscoelastic behaviour (creep and relaxation) of CCC is considered when evaluating material suitability for practical use, as are the restrained and unrestrained shrinkage properties. Estimation of such effects must be integrated into the design process [11-13]. Thus, long-term properties of CCC have been widely studied over the years, especially to acquire applicable knowledge about world-known and novel structural materials [14-18].

In terms of CCC mechanical properties, mainly qualities such as compressive strength and behaviour under sustained compressive loading have been researched and appreciated. Conventionally, in the design process of reinforced concrete, the CCC capacity of withstanding tensile stresses is neglected $[19,20]$. However, crack propagation under tensile loading is one of the main types of CCC failure mechanisms at the service limit state (along with crushing under compression at ultimate limit state), and even uniaxial compression failure can be considered as being due to tensile stresses [8,21]. Fibre reinforcement is proven to increase ductility, tensile and flexural resistance, as well as to diminish shrinkage at an early age and crack propagation [19,22-24]. To date, scientific progress has led to interests in various subfields of fracture mechanics and tensile bearing capacity with respect to diverse loading rates [21,25-27]. CCC tensile properties are investigated mainly by performing indirect tensile tests, where specific characteristic values can be derived. Direct uniaxial tensile tests are less common since it is problematic to maintain a test specimen within a loading rig under sustained uniform tensile stress $[14,20,25,28,29]$. Assessing the tensile strength of CCCs depends on the testing method used. The indirect tensile strength test provides higher strength than the direct uniaxial tensile tests, but the latter is considered more accurate [30,31]. Nevertheless, there is no standardised method for performing such a test [31].

RILEM TC232-TDT [32] recommends using parallelepiped shape specimens (with minimum dimensions of $500 \times 60 \times 6 \mathrm{~mm}$ ) for testing textile-reinforced concrete in uniaxial tension. The document recommends the use of LVDTs but also refers to ISO 9513 [33] regarding the required accuracy of extensometers. According to ISO 9513:2012 [33], extensometers can be either contacting or non-contacting (e.g., laser, DIC).

Digital image correlation (DIC) is a non-contact, optically based research technique that allows the monitoring of various derived quantities-of-interest (QOIs) at the surface of a test specimen. Through this method, point displacements, strains, surface curvature and velocities can be tracked. For such analysis, one (for 2D-DIC) or two (for 3D-DIC) digital cameras are used instead of conventional surface-attached measuring devices (e.g., linear variable displacement transformers or LVDTs, foil strain gauges, dial indicators, etc.). During the mechanical test, a specimen can be continuously monitored by recording a video or capturing images. Afterwards, the acquired images are processed by DIC software that evaluates the desired QOIs by analysing both point displacements and deviations from the initial state. The 2D-DIC technique is effective when the object is planar to the camera sensor and not moving with respect to the camera [34], whereas the 3D-DIC system (also known as stereo-DIC) tolerates relative movements and allows one to complete the calculations properly even with convex/concave-shaped specimens [35].

Cost-effectiveness is one of the reasons that researchers increasingly more often prefer non-contact measuring techniques over conventional systems. Since 2D-DIC is a monocular system and requires a single camera (with a stand, positioning mechanism and lighting kit), the expenses are significantly lower than for the 3D-DIC setup that requires at least double the amount of investment. Furthermore, computer software for 2D-DIC is normally less expensive (or even free of charge) and easier to operate. As 3D-DIC is beyond the scope of this research work, it will not be discussed in further detail. Various scientists have validated optical-based research techniques by using scientific-grade digital cameras. Such selection of equipment is also advised by the International Digital Image Correlation Society [34]. However, there have been successful studies that prove relatively inexpensive digital single-lens reflex (DSLR) cameras to be appropriate as well [36,37].

In practical use, the DIC technique can significantly ease surveys of CCC structures such as bridges, tunnel linings, containment vessels of nuclear reactors and others, that 
can be described as inaccessible to humans, hazardous environments or excessively large in the surface area $[38,39]$. Another advantage of DIC is the ability to analyse QOIs at any position and direction within the field of view (FOV). Therefore, unlike with surfaceattached measuring devices, with image correlation software, various changes can be evaluated that could not be predicted before the test (e.g., strain and crack propagation at unsuspected locations or amplitude) $[34,40]$. Furthermore, in some cases, deformations can exceed the limitations of the attachable extensometer gauge lengths and fastening accessories, leading to faulty data, an absence of data or even ending the test [37]. In general, the versatility of the DIC method allows it to be applied for both direct and indirect mechanical tensile testing.

In this research work, 2D-DIC was employed to monitor fibre-reinforced Portland cement composite tensile creep deformation. Compact Tension (CT) specimens were monitored under sustained uniaxially applied tensile load over 50 days. Similar specimen geometry is suggested by ISO 7539 [41], ASTM E647 [42] and ASTM E399 [43] standards. Such specimen geometry allows to investigate both elastic and plastic deformations as well as fracture mechanics. An entry/mid-level DSLR camera was used to capture the images, whereas the analysis was done using the GOM Correlate free software. In addition, the acquired data were compared with conventional surface-attached strain gauges measurements. Such long-term DIC experiments have not been previously done.

\section{Materials and Methods}

\subsection{Composite Mix}

For testing purposes, an OPC composite with $1 \mathrm{wt} \%$ (PVA) fibres was prepared. Detailed mix properties are given in Table 1. The composite was mixed and moulded into standard $150 \times 150 \times 150 \mathrm{~mm}$ oiled steel moulds. After curing for $24 \mathrm{~h} \mathrm{(in}+20^{\circ} \mathrm{C}$, wet conditions), the cubes were demoulded and submerged in water for seven days for hardening. Standard ageing conditions (temperature $20 \pm 2{ }^{\circ} \mathrm{C}, \mathrm{RH}>95 \pm 5 \%$ ) were provided during hardening.

Table 1. Cement composite mix.

\begin{tabular}{|c|c|c|c|}
\hline \multirow{2}{*}{ Component } & \multicolumn{2}{|c|}{ Quantity } & \multirow{2}{*}{$\begin{array}{c}\text { Water to } \\
\text { Cement Ratio }\end{array}$} \\
\hline & $\mathrm{kg} / \mathrm{m}^{3}$ & $w t^{2}{ }^{1}$ & \\
\hline Water (tap water) & 319.2 & & 0.5 \\
\hline Portland cement (Aalborg White, CEM I 52.5 R) & 638.4 & & \\
\hline Sand $(0.0-0.8 \mathrm{~mm})$ & 1276.9 & & \\
\hline $\begin{array}{l}\text { PVA fibres (mesofibres, } \mathrm{L}=12 \mathrm{~mm}, \varnothing 160 \mu \mathrm{m}, \\
\mathrm{E}=30 \mathrm{GPa} \text { ) }\end{array}$ & & 1 & \\
\hline $\begin{array}{l}\text { Superplasticizer Vinplast CL10 } \\
\text { (carboxylate-based) }\end{array}$ & & $0.09^{2}$ & \\
\hline
\end{tabular}

${ }^{1}$ Percentage by mass as a fraction of the total amount of mortar. ${ }^{2}$ Corresponds to $0.3 \mathrm{wt} \%$ as a fraction of the total amount of cement.

As shown in the mix properties, the obtained composite is characterised by a cementto-sand ratio of 1:2. PVA fibres were added to increase crack resistance, ductility and reduce shrinkage at anearly age of OPC concrete.

\subsection{Preparation of $C T$ Specimens}

The selected specimen shape resembles the one used for the evaluation of crack propagation in metals (ASTME647 [42]), the so-called Compact Tension (CT) specimen. Preparation of CT specimens was done after 7 days of curing. The cured composite cubes were saw-cut into $12 \mathrm{~mm}$ thick plates, using a stationary block cutter with a diamond saw blade. In cases of uneven cutting plane, the surface was manually smoothened with an angle grinder (with a diamond grinding disk). Clear access to the surface where the tensile creep strain progression becomes visible was important. To predict the maximum stress intensity zone and limit the FOV area (where the creep strains initiate), the $80 \mathrm{~mm}$ long 
and $0.5 \mathrm{~mm}$ wide notch was cut using a tabletop bandsaw Proxxon Micromot MBS 240/E (with a diamond blade). The tensile stress maximum intensity was achieved at the tip of the notch. The depth of the specimen was also reduced, promoting the plane stress state. The available path for the progress of the initiated strain parallel to the notch was $30 \mathrm{~mm}$. The distance between the loading axis and the tip of the notch was $50 \mathrm{~mm}$. Two drill holes with a diameter of $20 \mathrm{~mm}$ were made in further steps, where a stationary drilling machine (with a diamond drilling crown) was used. Summarising, the dimensions adopted for the specimens were $150 \mathrm{~mm}$ by $150 \mathrm{~mm}$ (perpendicular and parallel to the notch) and $12 \mathrm{~mm}$ (thickness). CT specimen geometry was prepared according to Figure 1. The preparation of such a methodology provides test specimens representing the situation close to real CCC structures since the fibres are oriented randomly and dispersed relatively evenly throughout the volume.
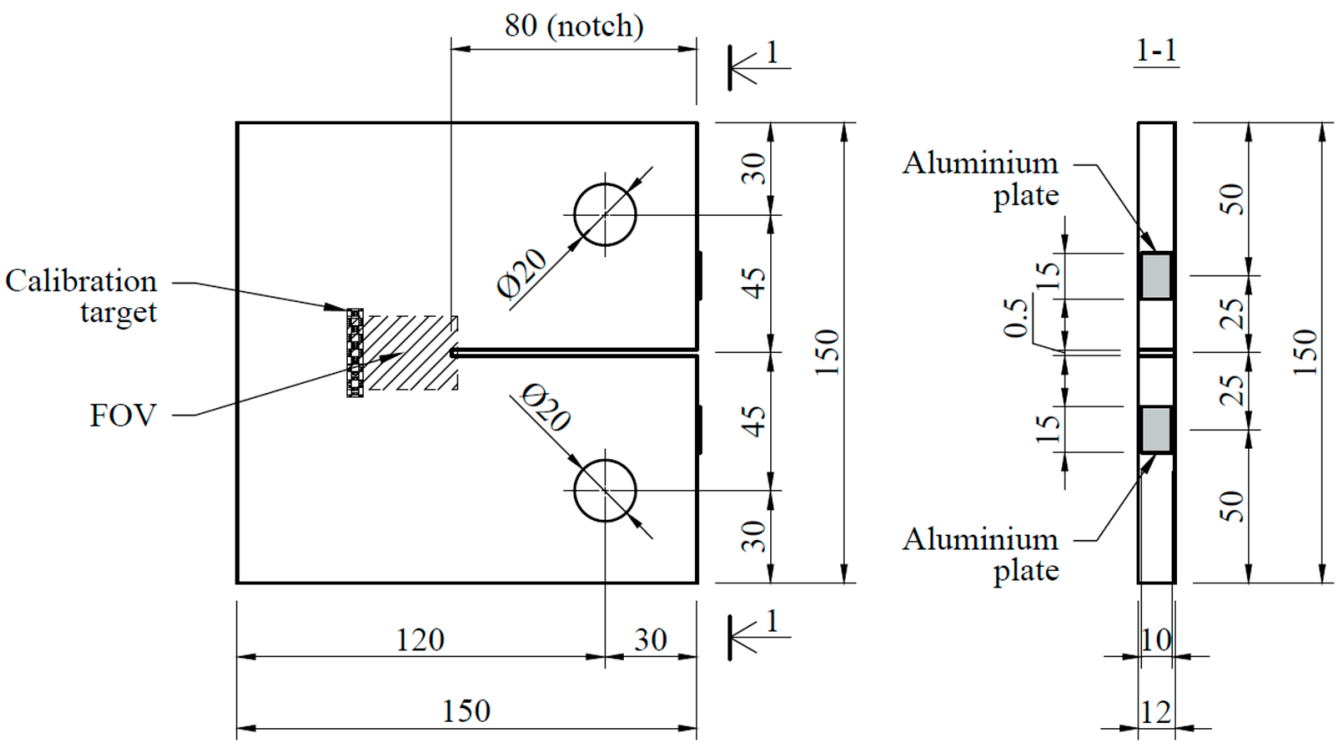

Figure 1. Compact Tension (CT) specimen.

When the specimens were finished, they were thoroughly cleaned under running tap water and dried in room condition $\left(+20{ }^{\circ} \mathrm{C}, \mathrm{RH}=60 \%\right)$ for $24 \mathrm{~h}$. After that, the region of FOV of each specimen was observed, and any protruding parts of the fibres were trimmed by hand using a thin razor blade. Trimming has a beneficial effect on further surface preparation. Such an action was also taken due to the previous trialling where unwanted shadows from sticking fibre ends were noticed (in the DIC images). In some cases, even such diminutive surface irregularities can complicate camera focusing (discussed in Section 2.3).

2D-DIC is based on such a principle that a unique surface pattern follows the deformed object itself while a mechanical test is performed. Then, several digital images are taken that capture changes throughout the time. Preferably, DIC software uses a dense stochastic speckle pattern at the surface of the test specimen to create overlapping subsets of points, matching and analysing deviations from the initial state (e.g., the first image in the series, also called the reference image) [34]. For applying a speckle pattern, an airbrush Royalmax TC-12K with black acrylic-based spray paint was used. In earlier trials, it was found that the speckle pattern tends to emanate and fade due to absorbing into the uncoated, porous surface of the material. Furthermore, in this research, white Aalborg cement was used for the mortar mix; thus, a bright white colour tone (close to RAL 9016) was obtained for the final hardened material. Because of such properties of the surface, the captured images happened to be overexposed (there was no valid solution found by adjusting the camera or the lighting settings). The DIC software could not evaluate the strains at the desired locations within the FOV. Considering previously mentioned obstacles, the surface of each test specimen was first coated with two layers of light grey (RAL 7047), 
nonglossy watercolour (applied with a brush). After $24 \mathrm{~h}$ of drying, black paint speckles were sprayed onto the coated surface region. Similar preparation technology has been used by L.Graziani et al. [44].

In the DIC software, real displacement values are calculated to user-defined reference intervals. Therefore, in this research, a surface-attached calibration target was glued to the specimen's surface and used within the FOV. The target with a $2.5 \times 2.5 \mathrm{~mm}$ checkerboard pattern was laser-printed on a self-adhesive plastic sheet (similar to standard copy paper $-0.1 \mathrm{~mm}$ in thickness). Ordinary office printing technology (laser-printing on non-coated paper) was shown to be less effective due to the limited sharpness of the printed borderlines between black and white regions.

Before experimental tests, two aluminium plates $15 \times 10 \times 0.8 \mathrm{~mm}$ were glued to the side of each specimen (using 2-part epoxy resin). After that, one digital dial gauge with $\pm 0.001 \mathrm{~mm}$ resolution was centrally and symmetrically positioned at the edge of each specimen. Strain gauges were placed so that their attachment points were located on the glued aluminium plates; the strain gauge length was $50 \mathrm{~mm}$. Strain gauges were attached to the specimens with elastic rubber bands (Figure 2).

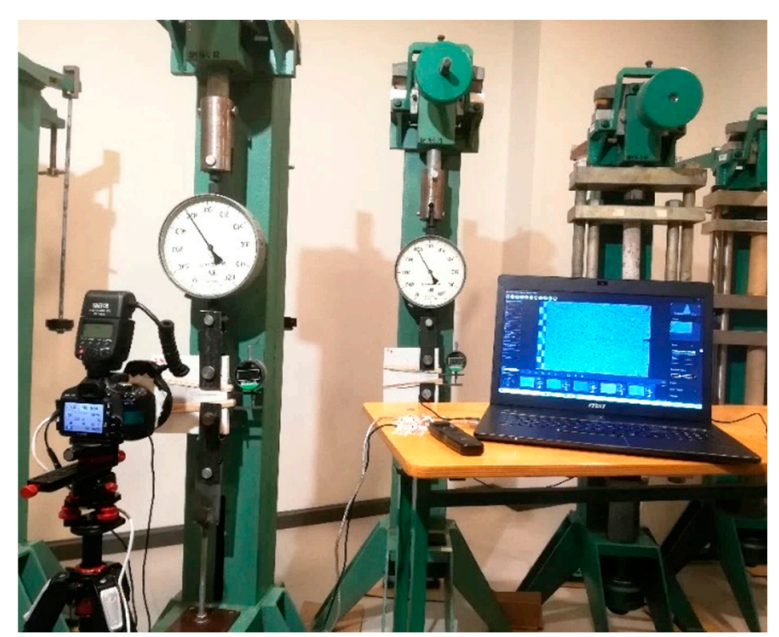

(a)

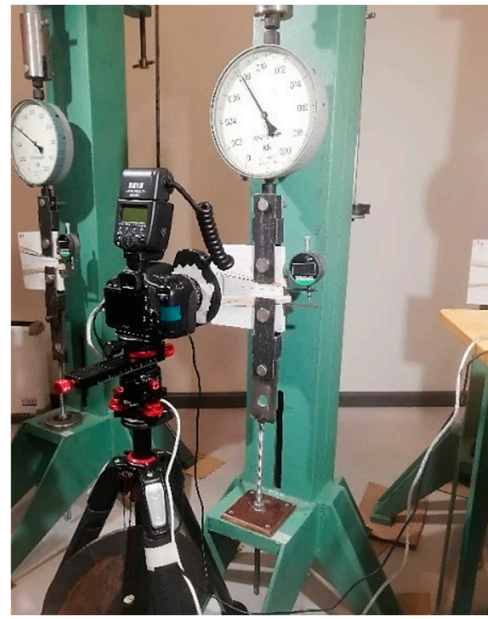

(b)

Figure 2. DIC imaging setup: (a) Camera facing the loaded test specimen, camera controlled via digiCamControl free software (FOV visible in the PC display); (b) camera tripod with stabilising weight, positioning mechanism, DSLR with macro ring flash, CT specimen with an attached strain gauge.

Then, each specimen was fixed into a lever arm creep rig and loaded. All creep specimens were loaded with a constant, static, tensile load and strain readings were regularly performed. In this case, for CT specimens, notch mouth opening displacement (NMOD) was monitored. Parallel to NMOD readings, the notch tip zone was captured daily with a digital camera (for further notch tip opening displacement-NTOD analysis). For detailed information about taking NTOD readings, please see Section 2.3.

On the first day of the long-term test, the strain readings were done before loading and after all the calculated load had been applied. For the first 6 to $8 \mathrm{~h}$, the readings were taken at hourly intervals. The next two-week readings were recorded at daily intervals. Then the following week, readings were taken at 2-3-day intervals. Similarly, to determine the correct creep behaviour, similarly shaped shrinkage specimens were placed in identical environmental conditions and their strain was monitored (no load applied to the shrinkage specimens). Conclusions were made based on subtracting the shrinkage strain values from the tensile creep values. The basic and drying creep components have not been determined separately. 


\subsection{Creep Test, DIC Application}

The CT testing procedures developed for the present work consisted of applying a tensile load to a single-edge notched specimen. Before the creep test, the ultimate tensile load was determined for the CT specimens. A universal testing machine with an accuracy of $\pm 0.5 \%$ for destructive ultimate load tests was used (rate of loading $0.3 \mathrm{~mm} / \mathrm{min}$ ). For creep tests, mechanical lever arm creep rigs were used. With these rigs, it is possible to apply constant loading to the specimens and to keep it uniform over a long period. Furthermore, it is not necessary to adjust the stress level during the experiments. The calibration curves are linear; no external energy resources are used. The lever arm ratio of the lever arm creep rig was 1:20. The loading level was adjusted to an accuracy of $\pm 2 \%$ (determined by an analogue dynamometer with $0.002 \mathrm{kN}$ resolution). The geometry of the test specimens was kept the same for all tests.

A single CT specimen was placed vertically in a creep rig, ensuring alignment with the loading axis. Each specimen was fixed (within the creep rig), using two grips (connected with bolts through the $\varnothing 20 \mathrm{~mm}$ drill holes) that transmit the applied tensile loading (Figure $2 \mathrm{~b}$ ). The fastening system was made so that the upper and lower attachment points are hinged (pinned) supports; hence, the specimen is free to rotate, and no additional stresses are caused due to eccentric loading. A more detailed description of the exact creep apparatus (inventory of Riga Technical University) can be found in [45]. Specimens were kept under constant load levels corresponding to $60 \%$ of the ultimate tensile load. A tensile dynamometer ДПУ-0.02-2 (resolution $0.002 \mathrm{kN}$, measuring range $0-0.2 \mathrm{kN}$ ) was enclosed within the loading rig to monitor precise levels of applied force. The load was applied gradually in five steps and as fast as possible. The modulus of elasticity was determined from the elastic strains that occurred at the beginning of the creep test. According to Hooke's law, the modulus of elasticity was determined by measuring the elastic strain on each loading step. After that, the specimens were kept under a constant load for 50 days. The long-term test was performed in a dry atmosphere of controlled relative humidity in standard conditions $\mathrm{t}=20 \pm 3{ }^{\circ} \mathrm{C}, \mathrm{RH}=50 \pm 5 \%$.

Complete creep testing and DIC imaging setup are shown in Figure 2. DIC imaging setup: (a) Camera facing the loaded test specimen, camera controlled via digiCamControl free software (FOV visible in the PC display); (b) camera tripod with stabilising weight, positioning mechanism, DSLR with macro ring flash, CT specimen with an attached strain gauge.

Previously, a similar DIC imaging setup was successfully used by M.Francic Smrkic et al. [37]. In this research work, the propagation of the tensile strain was traced on the surface of the specimens using a digital camera, Canon EOS550D DSLR (APS-C sensor) with the Canon EF-S $60 \mathrm{~mm}$ F/2.8 macro lens. The optimal distance between the camera sensor and the specimen was found to be $235 \mathrm{~mm}$, thus FOV was $36 \times 24 \mathrm{~mm}$. For optimal light conditions, a Meike MK-14EXT Macro Ring flash was attached to the lens. Due to insufficient sturdiness, extra rubber bands within the connecting junction and self-adhesive tape around the attachment ring were placed to hold the flash in a constant position (otherwise resulting in changing exposure). No additional external/ambient light sources were put to use.

The camera was placed on a tripod Manfrotto MT055XPRO3 (aluminium). For extra vibration resistance, a $2.1 \mathrm{~kg}$ weight was hung in the tripod's central node. For operational convenience, the camera fastening system (upon the tripod) was combined from several parts (listed upwards according to the placement on the tripod): Levelling head Puluz (with three adjustment screws), panorama head Rolley Pan Head R60, micropositioning rail Puluz, discal clamp FittestPhoto YP-65, quick release plate FittestPhoto PU-70 (for attaching to the camera). Such a setup allows to move and rotate the camera gradually relative to the test specimen.

Before loading, the camera was connected to a PC and trial images were captured via digiCamControl free software; the optimal camera settings were manually adjusted as follows: Aperture F/16, exposure time 1/25 s, ISO speed ISO-100, flash speed 1/64 s 
(no exposure compensation). Captured images were $5184 \times 3456$ px in size. Additionally, acquired images were checked with GOM Correlate software to evaluate pattern quality.

Since in 2D-DIC, it is crucial to prevent any camera movements from the initial position, all DIC images during the test were captured remotely using a wired shutter release device Jintu RS-60E3. DIC images were captured starting immediately after load application (in the loading rig) (according to the time intervals as mentioned in Section 2.2). Concurrently, displacement data were manually registered using an electrical dial gauge IP54 (resolution $0.001 \mathrm{~mm}$, measuring range $0-10 \mathrm{~mm}$ ) attached to the notched side of the CT specimen.

The acquired digital images were imported and processed in GOM Correlate free software-scaled in respect to the calibration target and analysed. The first image of the series (captured immediately after loading) was selected as the reference stage. To compare data from the DIC analysis to the electrical dial gauge, virtual extensometers were created in the software, from which data were exported for further analysis (image processing was done in accordance with [40]).

\section{Results and Discussion}

Figure 3 represents the stress/displacement distribution throughout the FOV area. There were three virtual extensometers (gauge length-10 $\mathrm{mm}$ ) placed in different areas of the FOV-close to the notch tip, central of the FOV and at the left edge of the FOV (along with the calibration target) (Figure 3) An additional virtual extensometer (gauge length $-10 \mathrm{~mm}$ ) was placed $1 \mathrm{~mm}$ into the notch area (beyond the FOV). The analysis was done using DIC software.

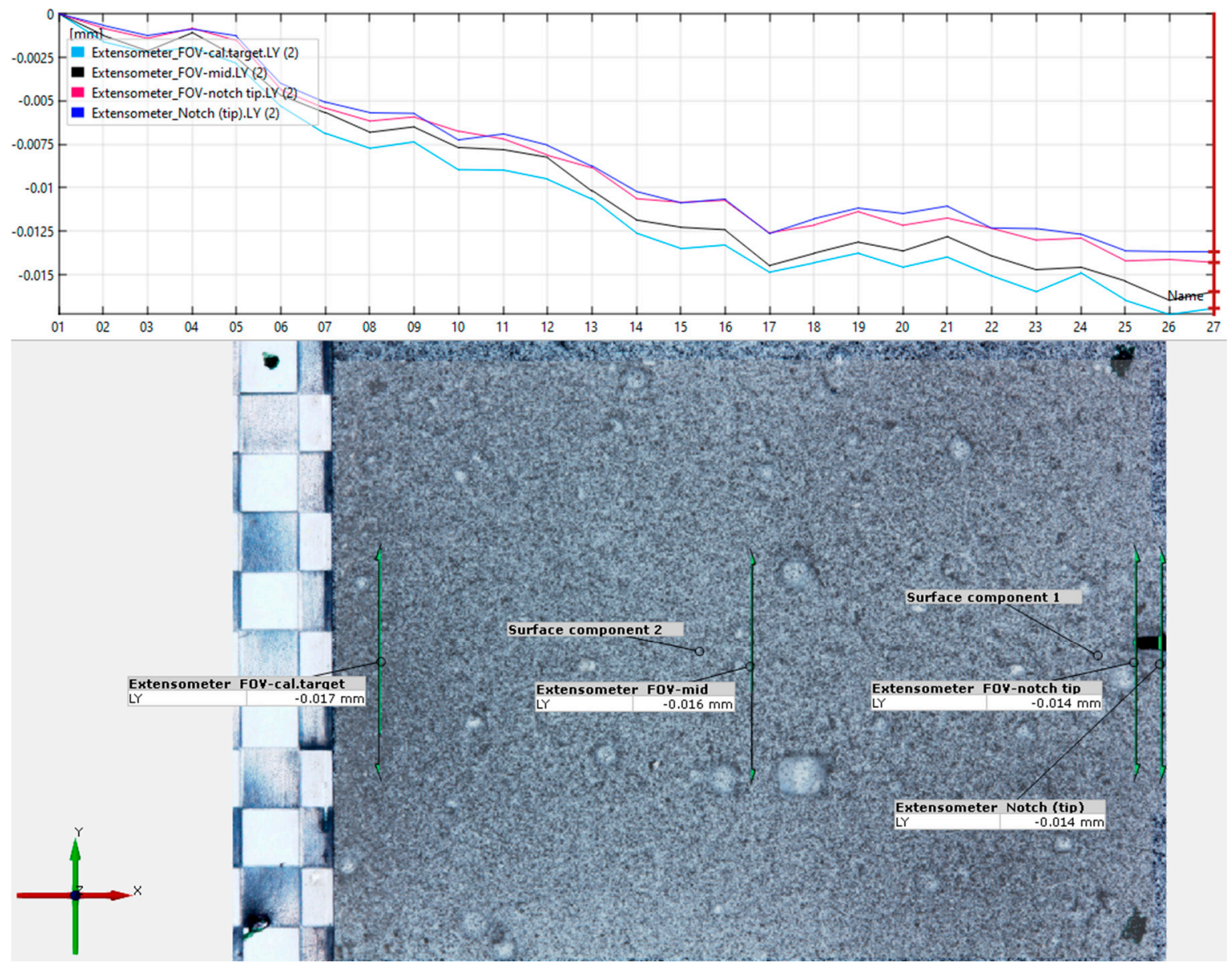

Figure 3. Analysis of stress/displacement distribution throughout the FOV area (image from GOM Correlate). 
The virtual extensometers used in the stress analysis were set to monitor distance changes relative to the reference stage (first image captured during the test). The graph reveals that the zones further from the notch tip are more prone to displacement than those that are placed closer and previously believed to bear higher strains. This subject is to be studied in more detail in further research.

In this experiment, the area of the CT specimen's notch tip was captured on a DSLR camera to compare the displacement data from the DIC with those registered by surfaceattached dial gauges. Five virtual extensometers (gauge length $-2 \mathrm{~mm}$ ) were created in GOM software for the DIC analysis. The extensometers were placed within the notched zone of the specimen $(0.5 \mathrm{~mm}$ into the notch towards the open end), positioned perpendicular to the notch (Figure 4). Such a location of the extensometers was chosen to enable displacement analysis (by DIC software) that can be verified with mathematical calculations (manually). Data represented by GOM software were exported to MS Excel for further analysis.
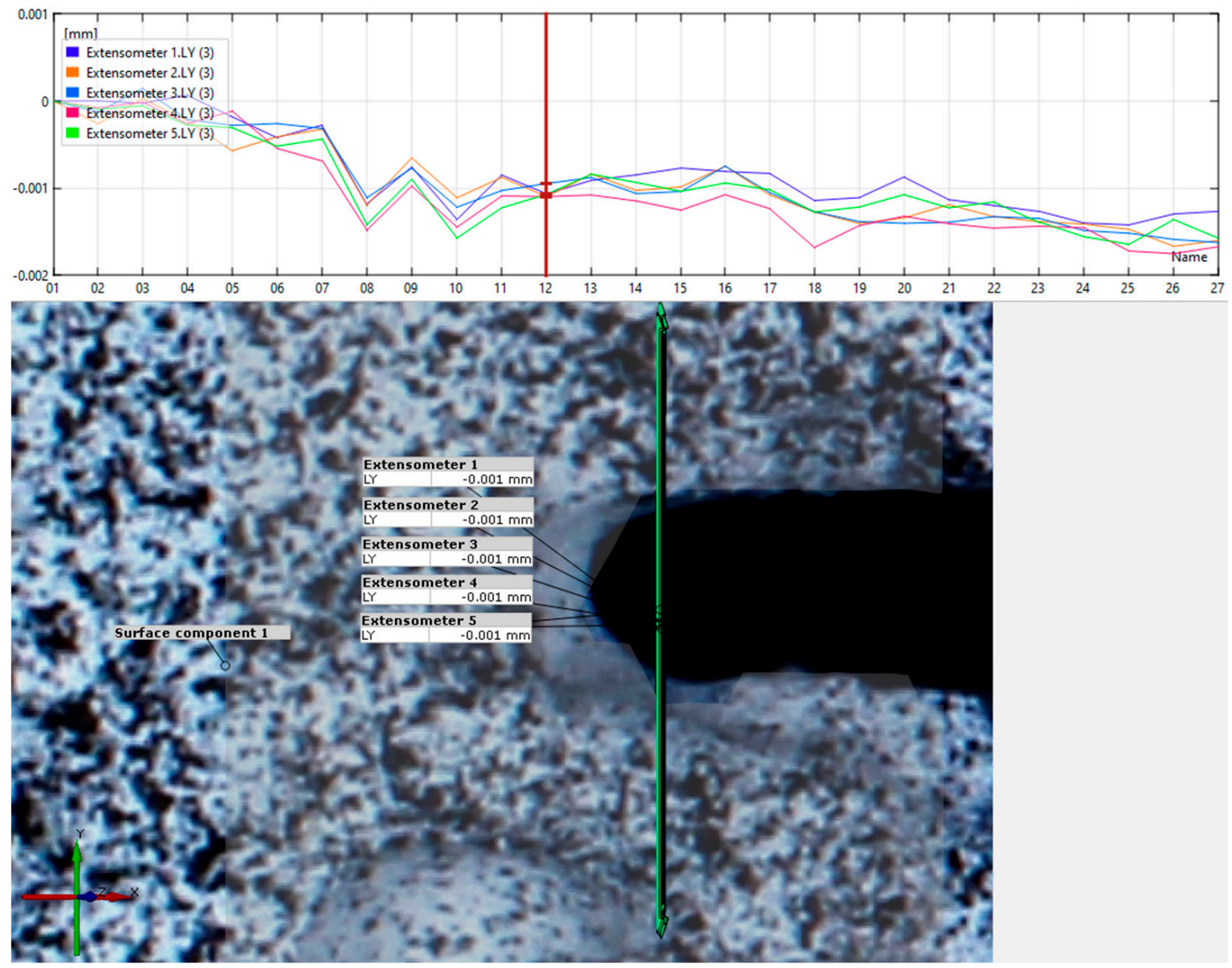

Figure 4. NTOD analysis with the DIC software (image from GOM Correlate).

In further analysis, all displacement data obtained from the DIC were compared with displacement data from surface-attached strain gauges. Figure 5 shows the test specimen with the measuring device and the data obtained.

Displacement data from surface attached digital dial gauge (NMOD) show similarities to data from the DIC analysis (NTOD) (Figure 6). Both curves are similar in their overall nature and tend to break simultaneously when showing reactions of the material (e.g., day 15 and day 24).

For further analysis of data compatibility, the mechanically measured displacements in the NMOD zone were used to mathematically calculate the corresponding NTOD values by similar triangles principle. The obtained results are shown in Figure 7. 
DIC analysis in GOM Correlate software shows a larger NTOD displacement compared to those calculated from the dial gauge data. The trend of both curves is similar.

Additionally, calculation principles by Saxena (1978) [46] were used to calculate the displacements along the loading axis (Figure 8).

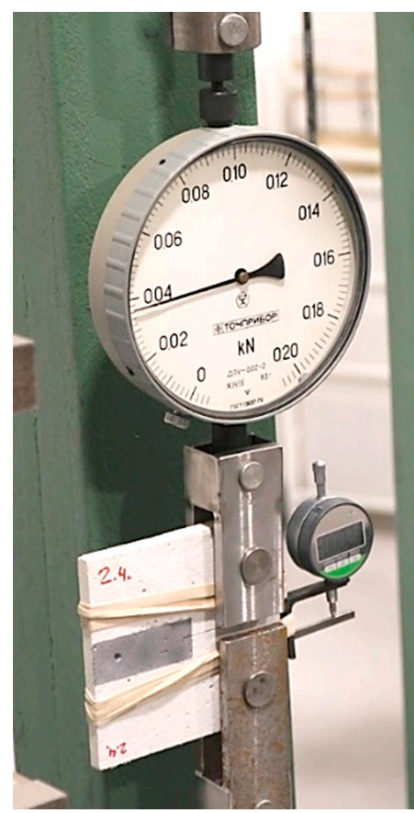

(a)

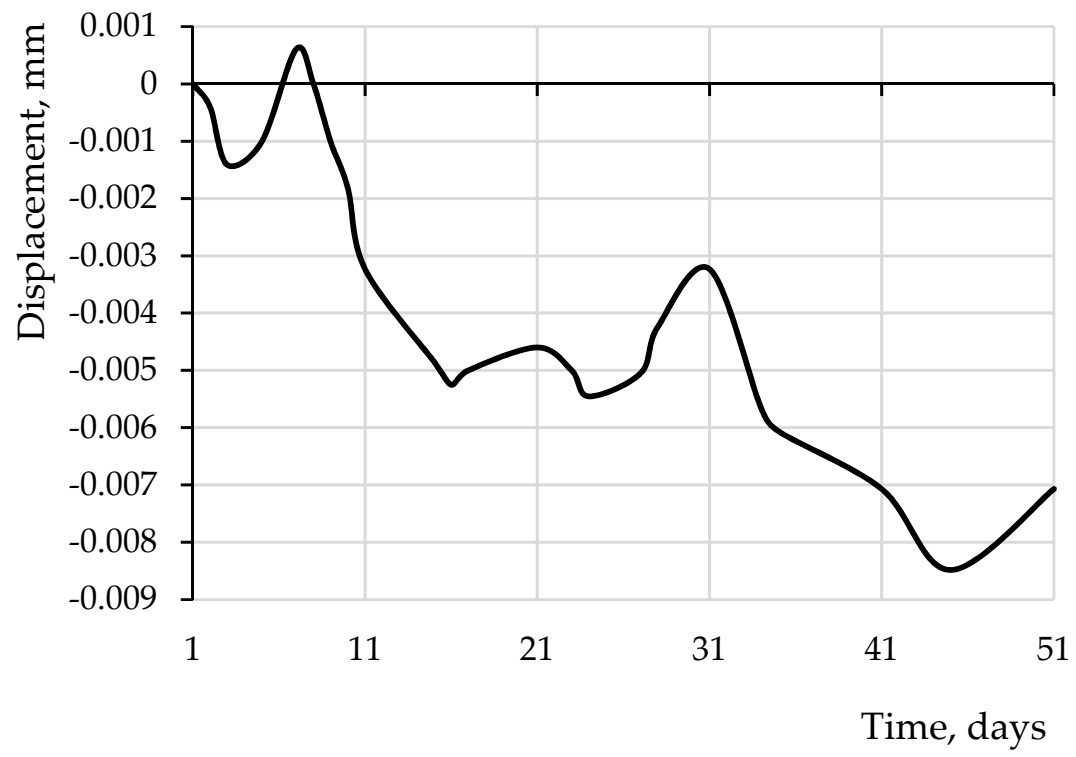

(b)

Figure 5. Creep monitoring with surface-attached strain gauge: (a) Test setup-loaded CT specimen with attached digital dial gauge; (b) displacement data obtained from a surface-attached strain gauge.

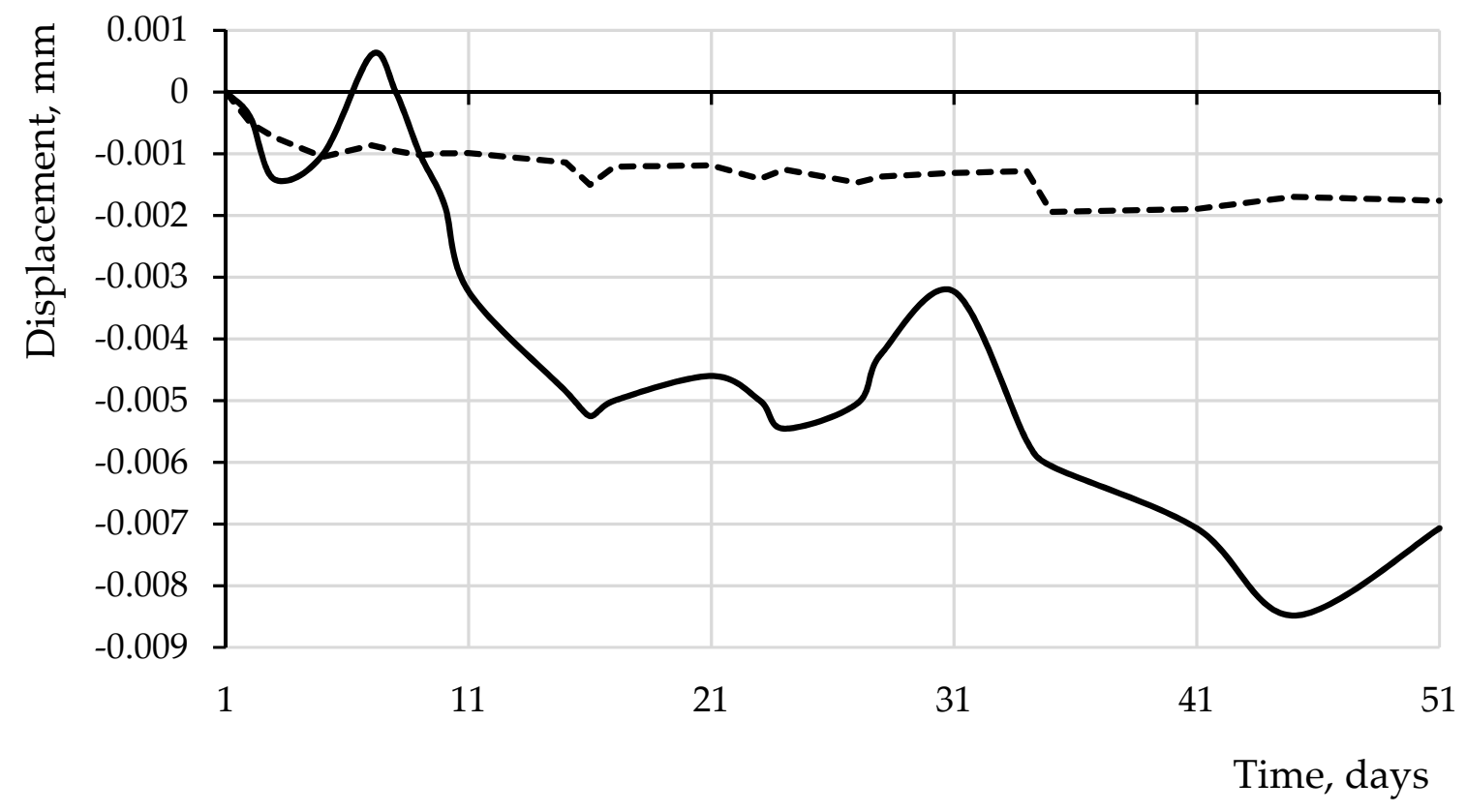

- NMOD (data from dial gauge) - - - NTOD (data from GOM Correlate)

Figure 6. Displacement data from surface attached digital dial gauge (NMOD) compared with data from DIC analysis (NTOD). 


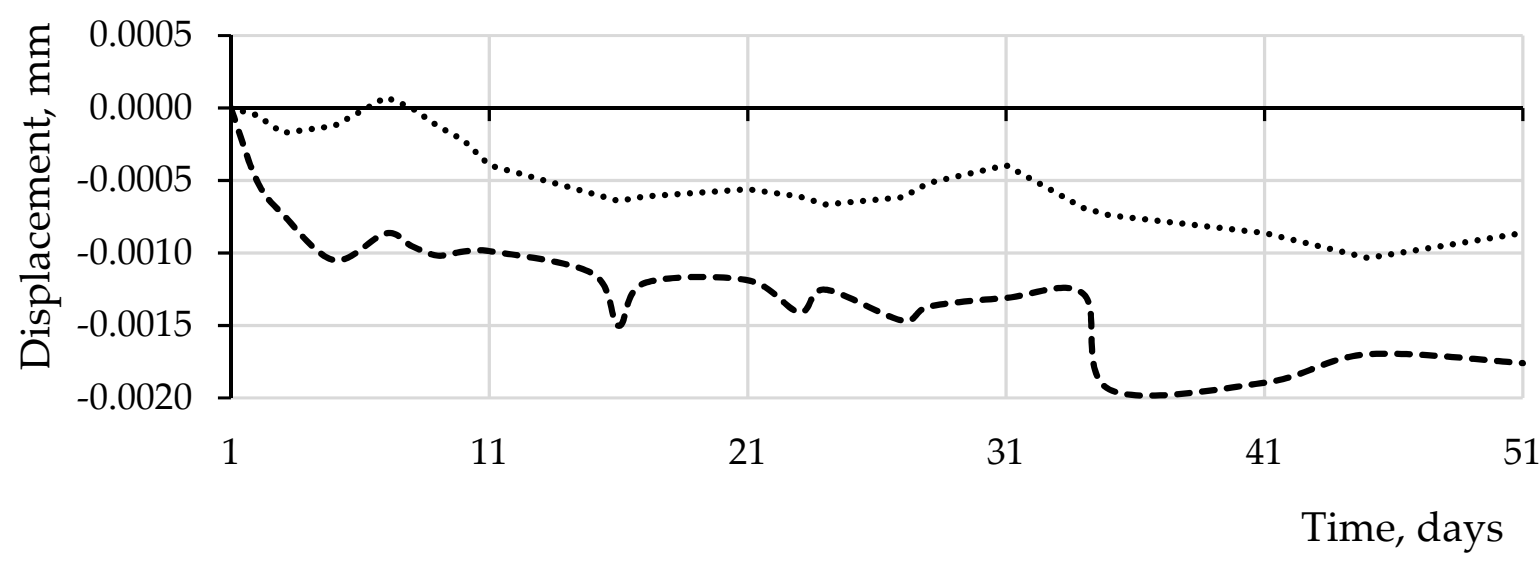

-----NTOD (data from GOM Correlate)

NTOD (calculated from dial gauge measurements data)

Figure 7. NTOD data from the GOM correlate compared to calculated NTOD data from physical measurements.

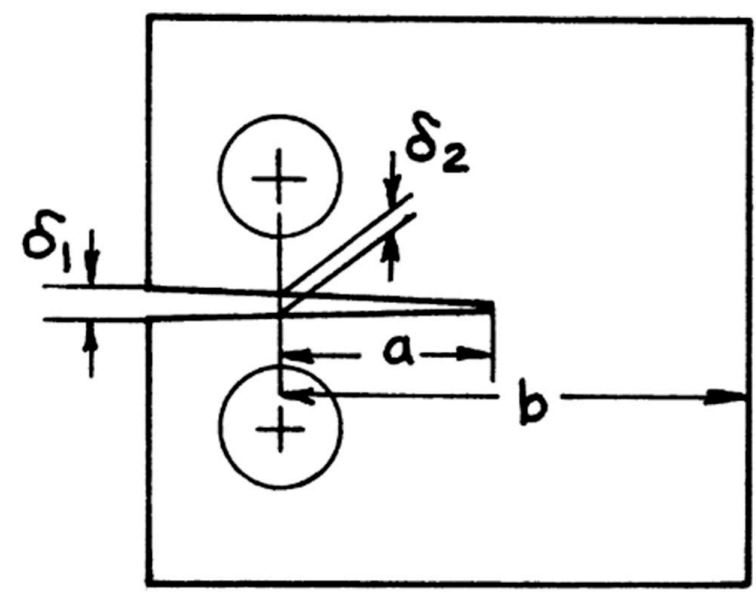

Figure 8. Displacement scheme for the CT specimens (by Saxena 1978) [46].

The following Equations (1)-(4) were used to calculate the displacements along the loading axis $\left(\delta_{2}\right)[46]$.

Opening at the crack edge:

$$
\delta_{1}=\frac{P}{E^{\prime}} V_{1}(a / b)
$$

Opening at load line:

$$
\delta_{2}=\frac{P}{E^{\prime}} V_{2}(a / b)
$$

Configuration functions for displacement:

$$
\begin{aligned}
& V_{1}(a / b)=\left(1+\frac{0.25}{a / b}\right)\left(\frac{1+a / b}{1-a / b}\right)^{2}\left[1.6137+12.678(a / b)-14.231(a / b)^{2}\right. \\
&\left.-16.610(a / b)^{3}+35.050(a / b)^{4}-14.494(a / b)^{5}\right] \\
& V_{2}(a / b)=\left(\frac{1+a / b}{1-a / b}\right)^{2}\left[2.1630+12.219(a / b)-20.065(a / b)^{2}\right. \\
&\left.-0.9925(a / b)^{3}+20.609(a / b)^{4}-9.9314(a / b)^{5}\right]
\end{aligned}
$$

where $P$ is the concentrated load and $E^{\prime}$ is the elastic constant. 
Equations (1)-(3) were applied so that $\delta_{1}$ represents NMOD and $\delta_{2}$ represents the displacement along loadline. Displacement values that were obtained from physical measurements, DIC analysis and mathematical calculations are shown in Figure 9.
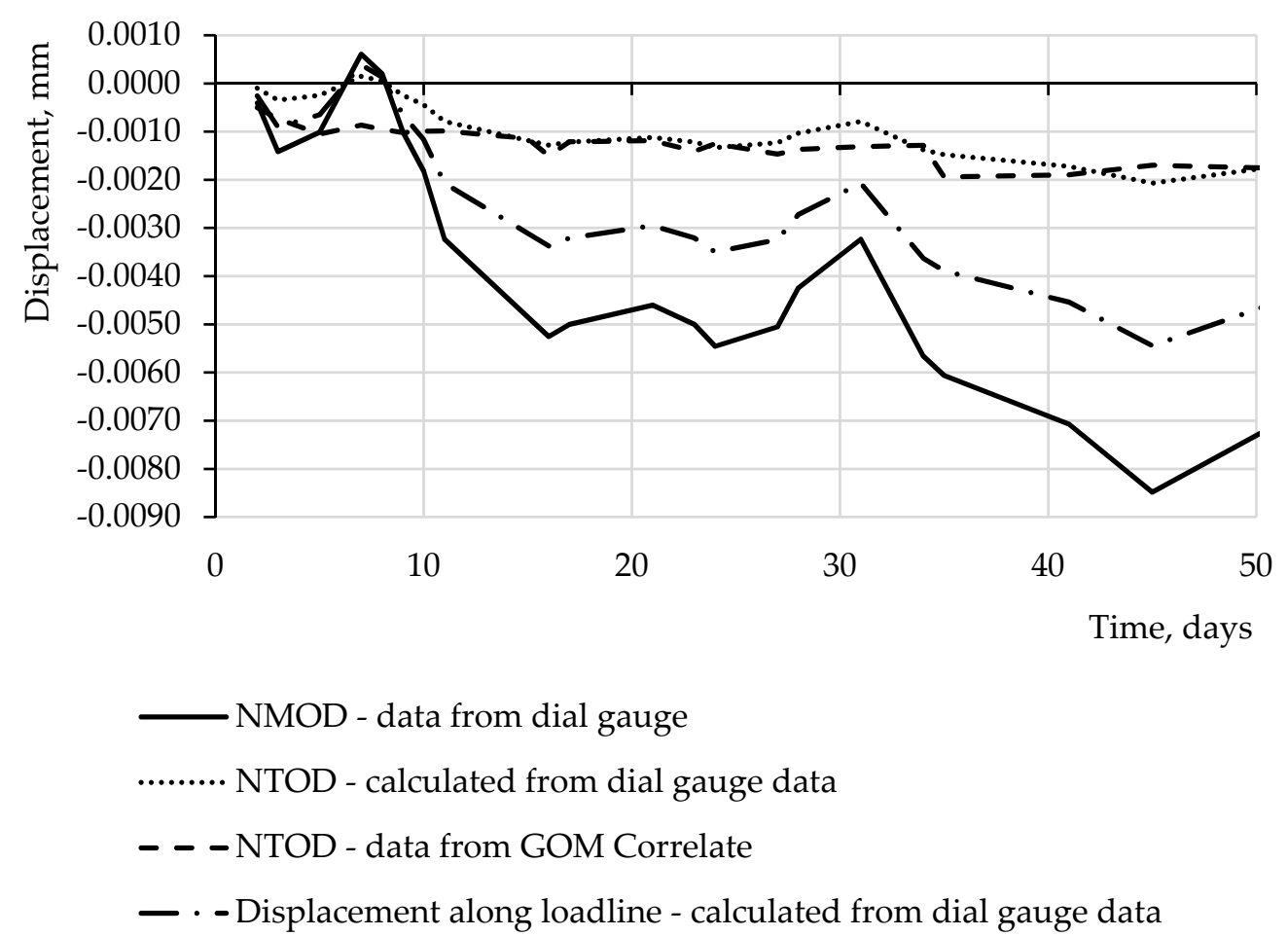

Figure 9. Displacement values are that obtained from physical measurements, DIC analysis and mathematical calculations.

As the calculations of displacement along the load line are dependent on the physically obtained displacement data, all displacement curves show close similarities in shape, whereas the absolute displacement values differ significantly. Such differences are reasoned by the unique geometry of a CT specimen - the deformation dynamic (under the designated load) at the free end of the notch is more rapid than the zone closer to the notch tip.

\section{Conclusions}

The use of 2D-DIC for Cement and Concrete Composite tensile creep monitoring has been successfully tested. Obtained experimental and computed data have been analysed to verify the compatibility of both conventional and innovative testing methods. The DIC imaging setup included an entry/mid-level DSLR camera that was proven to be suitable for testing long-term deformation properties. Thus, a new approach to Cement and Concrete Composite tensile creep research was verified. Results show that the applied testing method is suitable for studying cement and concrete composite tensile creep in uniaxial tension. Generally, the conventionally measured and computed NMOD and NTOD values for CT specimen displacement trends showed close similarities in their nature (characteristics of graph curves correspond) for both surface-attached and non-contact measuring techniques. The maximum tensile creep deformation of early age cement composite with PVA fibres after 45 days of constant tensile loading reached $0.0083 \mathrm{~mm}$ (NMOD) and $0.0055 \mathrm{~mm}$ (NTOD).

Further research needs to be carried out to study the mechanics of non-cracked Cement and Concrete Composite CT specimens. The finite element method may be employed to model behaviour of such Cement and Concrete Composite specimens under sustained load. Furthermore, general knowledge of related mathematical problems needs to be improved, especially regarding creep processes in such materials. 
Author Contributions: Conceptualization, A.S. and T.K.; methodology, A.S.; software, T.K., A.S. and J.V.; validation, T.K., A.S. and R.G.; formal analysis, A.S., T.K. and R.G.; investigation, A.S., T.K. and R.G.; resources, K.K.; data curation, T.K., A.S. and A.C.; writing-original draft preparation, A.S. and T.K.; writing-review and editing, R.G., J.V., K.K. and A.C.; visualization, T.K. and A.S.; supervision, A.S., K.K. and A.C.; project administration, A.S.; funding acquisition, K.K. and A.C. All authors have read and agreed to the published version of the manuscript.

Funding: This work has been supported by the European Regional Development Fund within the Activity 1.1.1.2 "Post-doctoral Research Aid" with the Specific Aid Objective 1.1.1 "To increase the research and innovative capacity of scientific institutions of Latvia and the ability to attract external financing, investing in human resources and infrastructure" of the Operational Programme "Growth and Employment" (No.1.1.1.2/VIAA/3/19/401). This work has been financed by the Polish National Agency for Academic Exchange under the International Academic Partnership Programme within the framework of the grant: E-mobility and sustainable materials and technologies EMMAT (PPI/APM/2018/1/00027).

Institutional Review Board Statement: Not applicable.

Informed Consent Statement: Not applicable.

Data Availability Statement: The study did not report any data.

Conflicts of Interest: The authors declare no conflict of interest.

\section{References}

1. CEN. EN 197-1; Cement Part 1: Composition, Specifications and Conformity Criteria for Common Cements; British Standards Institution: London, UK, 2011; ISBN 9780580682414.

2. Müller, C. Use of cement in concrete according to European standard EN 206-1. HBRC J. 2012, 8, 1-7. [CrossRef]

3. ASTM C125-03; Standard Terminology Relating to Concrete and Concrete Aggregates; ASTM International: West Conshohocken, PA, USA, 2003; pp. 1-4. [CrossRef]

4. ACI. Aci Ct-18. ACI Concrete Terminology. ACI CT-18. 2018. Available online: https://www.concrete.org/store/productdetail. aspx?ItemID=CT18\&Format=DOWNLOAD\&Language=English\&Units=US_Units (accessed on 27 August 2021).

5. Garcia-Lodeiro, I.; Palomo, A.; Fernández-Jiménez, A. An overview of the chemistry of alkali-activated cement-based binders. In Handbook of Alkali-Activated Cements, Mortars and Concretes; Elsevier: Amsterdam, The Netherlands, 2015; pp. 19-47. [CrossRef]

6. Torres-Carrasco, M.; Puertas, F. Alkaline Activation of Different Aluminosilicates as an alternative to Portland Cement: Alkali Activated Cements or Geopolymers. Rev. Ing. De Constr. 2017, 32, 5-12. [CrossRef]

7. Ashraf, W.; Olek, J.; Jain, J. Microscopic features of non-hydraulic calcium silicate cement paste and mortar. Cem. Concr. Res. 2017, 100, 361-372. [CrossRef]

8. Mehta, P.K.; Monteiro, P.J. Concrete: Microstructure, Properties, and Materials; McGraw-Hill Education: New York, NY, USA, 2014.

9. Hammodat, W.W. Investigate road performance using polymer modified concrete. Mater. Today Proc. 2021, 42, 2089-2094. [CrossRef]

10. Babafemi, A.J.; Boshoff, W. Testing and modelling the creep of cracked macro-synthetic fibre reinforced concrete (MSFRC) under flexural loading. Mater. Struct. 2016, 49, 4389-4400. [CrossRef]

11. Müller, H.S.; Acosta Urrea, F.; Kvitsel, V. Modelle zur Vorhersage des Schwindens und Kriechens von Beton: Teil 1: Analyse des Schwindmodells in DIN EN 1992-1-1:2011 und neuer Ansatz im Eurocode 2 prEN 1992-1-1:2020. Beton-und Stahlbetonbau 2021, 116, 2-18. [CrossRef]

12. Chateauneuf, A.M.; Raphael, W.E.; Moutou Pitti, R.J.B. Reliability of prestressed concrete structures considering creep models Struct. Infrastruct. Eng. 2014, 10, 1595-1605. [CrossRef]

13. Moga, C.; Gutiu, S.; Danciu, A.; Suciu, M. Concrete Shrinkage Stresses and Thermal Effects in the Composite Girders According To Eurocodes. In Proceedings of the 16th International Multidisciplinary Scientific GeoConference SGEM 2016, Albena, Bulgaria, 30 June-6 July 2016; pp. 501-508, ISBN 978-619-7105-69-8. ISSN 1314-2704.

14. Neville, A.M.; Dilger, W.H.; Walter, H.; Brooks, J.J. Creep of Plain and Structural Concrete; Construction Press: London, UK; New York, NY, USA, 1983; 361p, ISBN 9780860958345.

15. Atrushi, D.S. Tensile and Compressive Creep of Early Age Concrete: Testing and Modelling. Ph.D. Thesis, The Norwegian University of Science and Technology, Trondheim, Norway, 2003.

16. Matalkah, F.; Salem, T.; Shaafaey, M.; Soroushian, P. Drying shrinkage of alkali activated binders cured at room temperature. Constr. Build. Mater. 2019, 201, 563-570. [CrossRef]

17. Altoubat, S.A.; Lange, D.A. The Pickett Effect at Early Age and Experiment Separating its Mechanisms in Tension. Mater. Struct. 2002, 35, 211-219. [CrossRef]

18. Khan, I.; Xu, T.; Castel, A.; Gilbert, R.I.; Babaee, M. Risk of early age cracking in geopolymer concrete due to restrained shrinkage. Constr. Build. Mater. 2019, 229, 116840. [CrossRef] 
19. Mouton, C.J.; Boshoff, W.P. Initial study on the tensile creep of cracked steel fibre reinforced concrete. In Proceedings of the 8th RILEM International Symposium on Fibre Reinforced Concrete: Challenges and Opportunities (BEFIB 2012), Guimarães, Portugal, 19-21 September 2012; pp. 326-337, ISBN 978-2-35158-132-2.

20. Iskhakov, I.; Ribakov, Y. Structural phenomenon based theoretical model of concrete tensile behavior at different stress-strain conditions. J. Build. Eng. 2021, 33, 101594. [CrossRef]

21. Guo, R.; Ren, H.; Zhang, L.; Long, Z.; Jiang, X.; Wu, X.; Wang, H. Direct dynamic tensile study of concrete materials based on mesoscale model. Int. J. Impact Eng. 2020, 143, 103598. [CrossRef]

22. Afroughsabet, V.; Teng, S. Experiments on drying shrinkage and creep of high performance hybrid-fiber-reinforced concrete. Cem. Concr. Compos. 2020, 106, 103481. [CrossRef]

23. Babafemi, A.J.; Boshoff, W.P. Tensile creep of macro-synthetic fibre reinforced concrete (MSFRC) under uni-axial tensile loading. Cem. Concr. Compos. 2015, 55, 62-69. [CrossRef]

24. Si, W.; Cao, M.; Li, L. Establishment of fiber factor for rheological and mechanical performance of polyvinyl alcohol (PVA) fiber reinforced mortar. Constr. Build. Mater. 2020, 265, 120347. [CrossRef]

25. Abrishambaf, A.; Barros, J.A.O.; Cunha, V.M.C.F. Tensile stress-crack width law for steel fibre reinforced self-compacting concrete obtained from indirect (splitting) tensile tests. Cem. Concr. Compos. 2015, 57, 153-165. [CrossRef]

26. Körmeling, H.A.; Reinhardt, H.W. Strain rate effects on steel fibre concrete in uniaxial tension. Int. J. Cem. Compos. Lightweight Concr. 1987, 9, 197-204. [CrossRef]

27. Charron, J.P.; Desmettre, C.; Androuët, C. Flexural and shear behaviors of steel and synthetic fiber reinforced concretes under quasi-static and pseudo-dynamic loadings. Constr. Build. Mater. 2020, 238, 117659. [CrossRef]

28. Zi, G.; Oh, H.; Park, S.K. A novel indirect tensile test method to measure the biaxial tensile strength of concretes and other quasibrittle materials. Cem. Concr. Res. 2008, 38, 751-756. [CrossRef]

29. Chen, G.; Hao, Y.; Hao, H. 3D meso-scale modelling of concrete material in spall tests. Mater. Struct. 2015, 48, 1887-1899. [CrossRef]

30. Zheng, W.; Kwan, A.K.H.; Lee, P.K.K. Direct tension test of concrete. ACI Mater. J. 2001, 98, 63-71. [CrossRef]

31. Liao, W.C.; Chen, P.S.; Hung, C.W.; Wagh, S.K. An innovative test method for tensile strength of concrete by applying the strut-and-tie methodology. Materials 2020, 13, 2776. [CrossRef]

32. Brameshuber, W.; Hinzen, M.; Dubey, A.; Peled, A.; Mobasher, B.; Bentur, A.; Aldea, C.; Silva, F.; Hegger, J.; Gries, T.; et al. Recommendation of RILEM TC 232-TDT: Test methods and design of textile reinforced concrete: Uniaxial tensile test: Test method to determine the load bearing behavior of tensile specimens made of textile reinforced concrete. Mater. Struct. 2016, 49, 4923-4927. [CrossRef]

33. ISO 9513:2012. Metallic Materials-Calibration of Extensometer Systems Used in Uniaxial Testing. In Technical Committee: ISO/TC 164/SC 1 Uniaxial testing: France; International Organization for Standartization: Geneva, Switzerland, 2012.

34. Jones, E.M.; Iadicola, M.A. A good practices guide for digital image correlation. Int. Digit. Image Correl. Soc. 2018, 10. [CrossRef]

35. Helfrick, M.N.; Niezrecki, C.; Avitabile, P.; Schmidt, T. 3D digital image correlation methods for full-field vibration measurement. Mech. Syst. Signal Process. 2011, 25, 917-927. [CrossRef]

36. del Rey Castillo, E.; Allen, T.; Henry, R.; Griffith, M.; Ingham, J. Digital image correlation (DIC) for measurement of strains and displacements in coarse, low volume-fraction FRP composites used in civil infrastructure. Compos. Struct. 2019, 212, 43-57. [CrossRef]

37. Smrkić, M.F.; Košćak, J.; Damjanović, D. Application of 2D digital image correlation for displacement and crack width measurement on RC elements. Gradjevinar 2018, 70, 771-781. [CrossRef]

38. Yang, Y.S.; Wu, C. lin, Hsu, T.T.C.; Yang, H.C.; Lu, H.J.; Chang, C.C. Image analysis method for crack distribution and width estimation for reinforced concrete structures. Autom. Constr. 2018, 91, 120-132. [CrossRef]

39. Attard, L.; Debono, C.J.; Valentino, G.; Di Castro, M. Vision-based change detection for inspection of tunnel liners. Autom. Constr. 2018, 91, 142-154. [CrossRef]

40. GOM Company. GOM Correlate Professional V8 SR1 Manual Basic-Inspection-3D Testing. Manual 2015, 49, 1-127.

41. International Organization for Standartization. ISO 7539-9:2003 Corrosion of Metals and Alloys-Stress Corrosion Cracking-Part 9: Preparation and Use of Pre-Crack Specimens for Tests under Rising Load or Rising Displacement; International Organization for Standartization: Geneva, Switzerland, 2003.

42. ASTM. E647-Standard Test Method for Measurement of Fatigue Crack Growth Rates; ASTM: West Conshohocken, PA, USA, 2016.

43. ASTM. ASTM E399-12-Standard Test Method for Linear-Elastic Plane-Strain Fracture Toughness K Ic of Metallic Materials 1; ASTM: West Conshohocken, PA, USA, 2012.

44. Graziani, L.; Kneć, M.; Sadowski, T.; D’Orazio, M.; Lenci, S. Measurement of R-curve in clay brick blocks using optical measuring technique. Eng. Fract. Mech. 2014, 121-122, 1-10. [CrossRef]

45. Andina, S.; Kozlovskis, T. Experimental Methods and Apparatus for Investigation of Cement Composites' Creep, Shrinkage, and Cracking. Summary; Riga Technical University: Riga, Latvia, 2020; pp. 1-39.

46. Tada, H.; Paris, P.; Irwin, G.R. Stress Analysis of Cracks Handbook, 3rd ed.; Tada, H., Ed.; ASME Press: New York, NY, USA, 1973. 